Research Article

\title{
Perceived Individual Cultural Values and Erp Users: The Case of Saudi Arabia
}

\author{
Dr. Hisham Al hirz
}

Assistant Professor, Director of Postgraduate studies, COBA Faculty, MIS, Al Yamamah University, Saudi Arabia

\begin{abstract}
The purpose of this paper is to examine the influence of espoused national cultural values of individuals on user mental acceptance of enterprise resource planning (ERP) systems. Such an influence is mediated by perceived software quality, and perceived user satisfaction with ERP. The structural equation model shows evidence for power distance, and uncertainty avoidance influencing perceived software quality of ERP, even though their influences are relatively weak. Individualism, however, has no significant influence over perceived software quality, while perceived user satisfaction impacts user mental acceptance of ERP. This paper contributes to the body of ERP studies, as (1) validating the influence of cultural values as an independent and external factor impacting the behavioural adoption of ERP users, (2) applying the paradigm of Bagozzi framework to behavioural adoption and acceptance of Information Systems (IS) and (3) contributing to ERP studies in the Middle East from cultural and quantitative perspectives.
\end{abstract}

Key words: Enterprise systems, Culture, Behavioural adoption, Mental acceptance.

\section{Introduction}

ERP is a software system designed to enable organisations to become competitive and substantially increase the effectiveness of their business internally and externally. ERP is a means to standardise organisational business processes to provide operational, managerial, strategic, infrastructure and organisational benefits (Shang and Seddon 2000). It provides integration of the complete range of a business' processes and functions in order to present a holistic view of the business from a single information and Information Technology (IT) architecture, allowing organisations to foresee emergent opportunities for continuous improvement (Klaus, Rosemann et al. 2000). However, ERP projects are difficult to initiate because of the effort required in terms of time, money and expertise. Since ERP imposes its way of doing business (Davenport 1998) and requires a critical understanding of how changes impact organisations and users, it is important to study ERP user behaviours to reveal how cultural differences impact IT adoption (Lee, Trimi et al. 2013).

It is arguable that ERP implementation is less likely to face technical failures as a result of advances made over the two decades since ERP introduction's to the market. However, ERP implementation is more likely to encounter managerial problems that cause organisational and user resistance to its adoption (Jagoda and Samaranayake 2017). ERP implementation normally creates changes associated with job content, social status, control and power, and decision-making processes (Lapointe and Rivard 2005). As a result, employees who are affected by these changes are more likely to become resistant to accepting ERP systems (Klaus and Blanton 2010). For example, during its implementation, the various views of ERP implementers, vendors, top management and operational users are more likely to escalate managerial conflicts regarding how early and later ERP implementation requirements should be met. However, ERP operational and non-operational users are likely to perceive their interactions with the software differently depending on individual differences and social influences such as cultural values and experience (Srite and Karahanna 2006; Venkatesh and Bala 2008). This, in turn, is more likely to create a group of ERP users who vary in their perceptions of adoption or usage of the software even though ERP is mandatory in nature (Alhirz and Sajeev 2015). This variation is likely related to how individuals with espoused national cultural values of power distance (PDI), uncertainty avoidance (UAI) and individualism (IDV) perceive these values in relation to ERP features such as integration, reliability and customisability (Molla and Loukis 2005). The question, therefore, is about the extent to which these national culture values at the individual level are likely to influence user perceptions of software quality attributes, which in turn impact user satisfaction and behavioural adoption of ERP systems (Delone and Mclean 2003; Venkatesh and Bala 2008; Rabaa'i 2009).

Culture plays a major role in ERP implementation, as most ERP studies have shown (Davison 2002; Chadhar and Rahmati 2004; Liang and Xue 2004; Sheu, Chae et al. 2004; Zhang, Leeb et al. 2005; Rajapakse and Seddon 2006). Most of these studies, however, rely on theory development via case studies because this allows them to analyse ERP as an outcome of human actions and interactions with technology. This, in turn, allows researchers to consider 'the social setting of the organisation that shapes technology and vice versa' (Boersma and Kingma 2005). In fact, the adoption and acceptance of ERP from the perspectives of individual 


\section{Dr. Hisham Al hirz / Perceived Individual Cultural Values and Erp Users: The Case of Saudi Arabia}

differences in cultural dimensions, such as PDI, UAI, and IDV, has received relatively little attention (Kappos and Rivard 2008; Venkatesh and Zhang 2010). This may explain why most ERP studies have taken the form of case studies in the Middle East, though there is still a lack of such studies in these non-Western countries. This suggests a gap in the body of ERP studies in the Middle East, related to cultural factors within user adoption and acceptance of ERP, seen in quantitative studies in Saudi Arabia in particular (Saleh, Abbad et al. 2013). In fact, the adoption and acceptance of ERP from the perspectives of individual differences in cultural dimensions, such as PDI, UAI, and IDV, has received relatively little attention (Kappos and Rivard 2008; Venkatesh and Zhang 2010). This paper, therefore, hopes to enrich this direction of ERP studies and provide insights into ERP user behaviour in the context of Saudi Arabia. On the one hand, it provides an integrative view, as psychological contract theory is used to explain the relationship between user perceptions of national culture at the individual level and their impacts on user perceptions of software quality attributes. On the other hand, the framework of Bagozzi (2007) for user adoption and acceptance of IS is used to provide a theoretical explanation of how perceived quality, perceived user satisfaction and symbolic adoption are interrelated. This, therefore, bridges the gap between the theory and practice of IS usage.

Different theoretical constructs were applied to examine user adoption and acceptance of ERP. The technology acceptance model (TAM) has been widely employed in the context of ERP studies. The applicability of TAM, however, has been challenged across cultures (McCoy, Galletta et al. 2007), and also because of the given complex and mandatory nature of IS (Hsieh and Wang 2007; Al-Jabri and Roztocki 2015). This is probably why IS scholars incorporate additional factors to develop a better understanding of factors influencing the behavioural adoption of ERP users (Nah, Tan et al. 2004; Amoako-Gyampah 2007; Sternad, Gradisar et al. 2011; AlJabri and Roztocki 2015). Most extensions of technology acceptance models appear to have not considered the individual differences in the cultural dimensions of PDI, UAI and IDV as independent and external factors influencing the behavioural adoption of ERP users (Venkatesh and Zhang 2010; Venkatesh, Thong et al. 2012). As Venkatesh and Zhang (2010) suggest, future investigations are encouraged to examine the direct or indirect influences of these cultural values on the behavioural intentions of IS users. This enriches ERP studies in three ways: (1) validating the influence of cultural values as an independent and external factor impacting the behavioural adoption of ERP users, (2) applying the paradigm of Bagozzi (2007) to behavioural adoption and acceptance of IS and (3) contributing to ERP studies in the Middle East from cultural and quantitative perspectives.

This paper is organised as follows. First, the concept of Psychological Contract Theory and specifically its employment in the ERP context is explained. Second, Bagozzi's (2007) framework of behavioural adoption and acceptance of IS is examined. Third, the research variables and hypotheses are introduced and explained. The paper is concluded with a discussion of findings, future research and research limitations.

\section{Theoretical foundation}

This section will explain the concepts of psychological contract theory and the new paradigm of Bagozzi (2007) of behavioural adoption and acceptance of IS. These theories are adopted to provide a constructive understanding of how the relationships between our research variables are modelled.

\section{Psychological Contract Theory}

Psychological contract theory is defined as 'beliefs that individuals hold regarding promises made, accepted, and relied on between themselves and another' (Rousseau, 1995, p. 9 cited in Klaus and Blanton 2010). It is subjective and dynamic in nature because it depends on the employee's changing expectations. It is therefore a subjective understanding of what an employee believes his/her superior or employer is required to provide. It provides an explanation of how employees perceive their responses to organisation change and how psychological contract breaches are formed. A considerable psychological contract breach has been termed as 'violation', and this may cause the employee to have 'an affective and emotional experience of disappointment, frustration, anger, and resentment' (Klaus and Blanton 2010). Figure 1 shows how a perceived unmet promise can lead to a psychological contract breach or violation. If there is a perceived unmet promise, an employee compares his or her own contributions to the organization to the amount of reciprocal contributions by the organization. Based on this comparison, a psychological contract breach is formed. When the breach occurs, the employee starts interpreting it in light of fairness judgments, outcome assessments, and other considerations to determine whether a severe perceived breach of contract, or violation, has occurred.

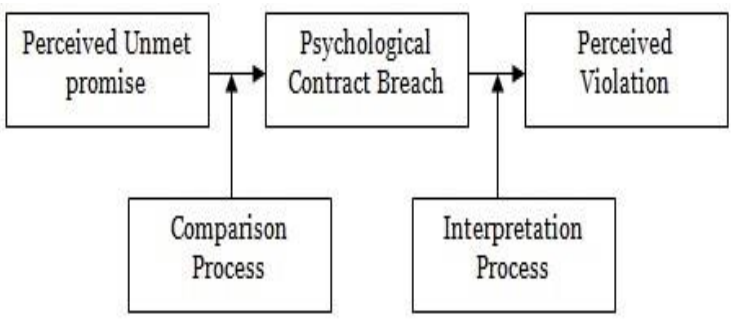

\section{Figure 1 Development of Violation}

(Morrison and Robinson, 1997 cited in Klaus, Wingreen et al. 2010)

As Klaus and Blanton (2010) explain, the psychological contract has been studied primarily in the psychology and management literature; however, they employ this theory to better understand the development of user resistance to ERP. Their findings, however, suggest that twelve determinants divided into four key dimensions contribute to influencing the psychological contract, which in turn impacts the level of user resistance to ERP (Table 1). However, psychological contract theory is adopted in a way that provides us with a theoretical 


\section{Dr. Hisham Al hirz / Perceived Individual Cultural Values and Erp Users: The Case of Saudi Arabia}

understanding of why ERP users perceive their interaction with their software quality attributes as positive or negative. Later discussion, however, will explain the relationship between perceived culture at the individual level and software quality attributes when discussing the research model and its interrelationships.

Table 1 User Resistance Determinates Framework

\begin{tabular}{|l|l|}
\hline Key Dimension & Determinant \\
\hline Individual issues & $\begin{array}{l}\text { uncertainty, input, control, } \\
\text { power, self-efficacy }\end{array}$ \\
\hline System issues & $\begin{array}{l}\text { technical problems, } \\
\text { complexity }\end{array}$ \\
\hline Organisational issues & $\begin{array}{l}\text { facilitating environment, } \\
\text { communication, training }\end{array}$ \\
\hline Process issues & $\begin{array}{l}\text { job/job skills change, lack of } \\
\text { fit }\end{array}$ \\
\hline
\end{tabular}

(Klaus and Blanton 2010)

\section{Bagozzi's Framework}

This section must be in one column. Bagozzi (2007) finds that the theoretical relationship of TAM constructs is poor: Behaviour should have been treated as a tool to achieve a fundamental goal, and actual use should not be represented by intention since uncertainties could play a role in the time period between intention and adoption and might affect the decision to accept technology. Therefore, he proposes a shift in the paradigm of user adoption and acceptance of IS (Figure 2):

(1) The model consists of a decision making core (goal desire $\rightarrow$ goal intention $\rightarrow$ action desire $\rightarrow$ action intention) that has its root in basic decision-making variables/processes of a universal nature. The decision core also includes a mechanism for self-regulation that moderates the effects of desires on intentions. (2) In addition to the decision-making core, there are a number of causes and effects of decisions and selfregulatory reasoning, with the aim of introducing potential contingent, contextual nuances for understanding decision making. Self-regulation, however, can be reflective or reflexive. Reflective self-regulation, on the one hand, is defined as the active imposition of personal moral or selfevaluative standards to a felt or possible goal desire or action desire. Reflexive self-regulation, on the other hand, is related to learned values, dispositions, traits, virtues, and vices.

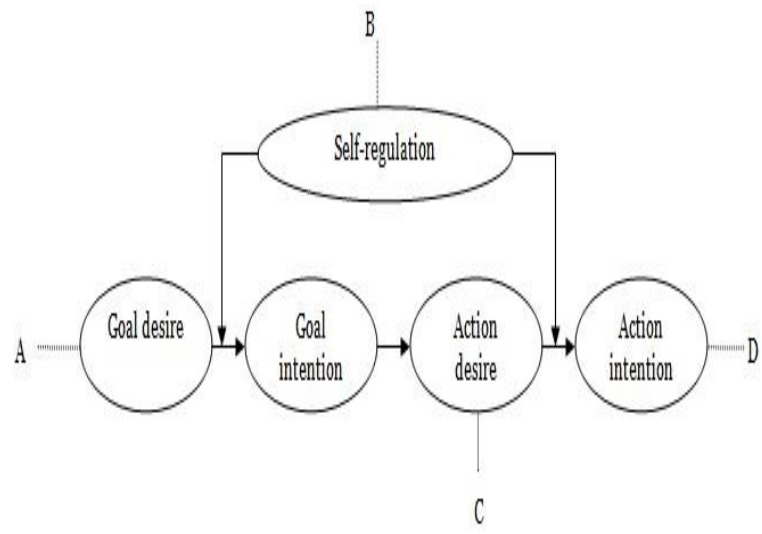

Figure 2 The Decision-Making Core
(Bagozzi 2007)

These processes and their causes or constraints are labelled as $\mathrm{A}$ and $\mathrm{B}$ in the above figure, and their effects labelled as D represent deterministic processes. These processes depict the basic stages in decision making, bridging goal setting (A) and goal striving (D), making overall goal-directed behaviour the centre of focus for user acceptance (see Bagozzi (2006) for further discussion). The adoption of this paradigm is therefore done to provide a solid theoretical base that supports the interrelationships of how perceived quality attributes are likely to influence satisfaction which in turn influences behavioural adoption of ERP users.

\section{The proposed research model and development of hypotheses}

The motivation for developing this model is to examine the extent to which perceived culture values at the individual level as well as software quality attributes play a role in user acceptance of ERP. In non-Western environments, there are 'sizeable gaps between the assumptions and requirements built to ERP system design and the actual realities of the client organisation' (Hawari and Heeks 2010). This gap is likely to minimise the level of behavioural adoption of ERP users despite its mandatory use, and is also likely to impact organisational performance in the long-run. Some organisations, for example, are likely to seek inclusions of additional ERP features and modules during partial or complete success of ERP implementation, and this creates additional pressure on ERP users to develop skills, or adopt changes on a regular basis. This model, therefore, explores how ERP user perceptions of national culture values at the individual level are likely to influence their perceptions of software quality attributes, and how this relationship impacts satisfaction and behavioural adoption and acceptance of ERP users in a Saudi context.

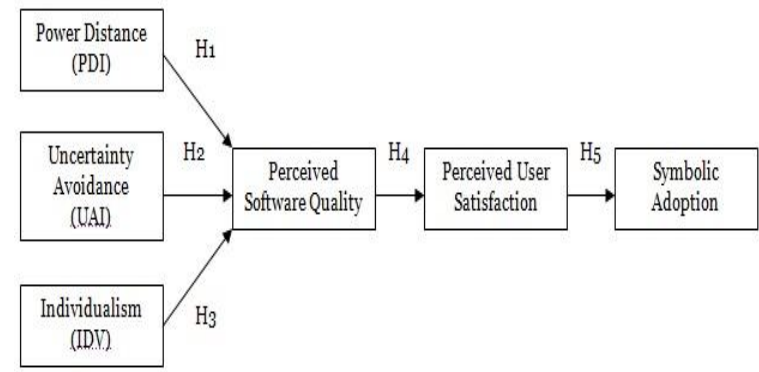

Figure 3 The Research Model

Hofstede (1980) defines culture as 'a collective programming of the mind which distinguishes one group from another'. This explains why scholars stress the term 'shared values' as a central element that is a distinguishing characteristic of a culture. Values, therefore, underlie 'relationships among abstract categories that are characterized by strong affective components and imply a preference for a certain type of action' (Straub, Loch et al. 2002). They are beliefs individuals hold that enable them to determine their personal or social course of action. Values are obtained early in life (Geertz 1973; Hofstede 2001), while family, neighbourhood and 


\section{Dr. Hisham Al hirz / Perceived Individual Cultural Values and Erp Users: The Case of Saudi Arabia}

school play a major role in shaping one's 'mode of conduct or end-state of existence'. Once a value is acquired, it becomes a part of an organised system of values where each value has a relative priority (Straub, Loch et al. 2002). This suggests that values are not of equal weight and their importance varies across individuals (Lachman 1983). Besides, as the value system is developed and has its shape within individuals, it 'is relatively stable in nature but can change over time reflecting changes in culture as well as personal experience' (Straub, Loch et al. 2002); in other words, unique experiences influence individual value systems and also the extent to which these values are stable.

System users most likely perceive IS through their own cultural values, norms and beliefs, and therefore different individuals are likely to experience different reasons behind their adoption of technology. Incorporating cultural values is therefore necessary for users to successfully use IS; however, the question then is how to measure cultural values. Researchers have proposed several measures for national culture (e.g. Hall 1976; Hofstede 1991) of which Hofstede's work is more commonly used in information systems research.

Molla and Loukis (2005) explain that during the implementation and use of ERP, there is "ERP software culture" reflecting the views of the ERP developers, vendors and consultants and "host culture" reflecting the perceptions of the implementing organisation's project team, managers and users. The differences in the two "cultures" can be more vivid when the software developed primarily in the west is implemented in organisations in the east (Alhirz and Sajeev 2015). The influence of culture on ERP acceptance is contextualised within the national cultural dimensions suggested by Hofstede's theory because these dimensions influence the implementation or user adoption and acceptance of ERP (Sheu, Chae et al. 2004; Rajapakse and Seddon 2006) and recent studies emphasise the direct and indirect effect of national culture on behavioural adoption and acceptance of IT (Venkatesh and Zhang 2010).

Based on research in cultural psychology (e.g. Tyler, Lind et al. 2000) and information systems (e.g. Straub, Loch et al. 2002), Srite and Karahanna (2006) posited that "national culture impacts the cultural values an individual holds, which in turn influence technology acceptance". Consequently, they have argued that national cultural values can vary substantially from individual to individual and therefore it is important to study the influence of espoused cultural values of individuals on technology acceptance. We follow Srite and Karahanna's approach, but, in studying whether differences in espoused national cultural values of ERP users will influence ERP adoption.

The cultural dimensions we use are power distance, uncertainty avoidance and individualism. Two other dimensions of culture, long-term orientation and masculinity were not considered for the following reasons. Hofstede introduced long term orientation as a factor influenced by the Confucian philosophy (Hofstede and Bond 1988), which is alien to the culture of Saudi Arabia. Similarly, for historical reasons, Saudi Arabia had a predominantly masculine culture with traditionally very little participation in the industrial workforce from women, thus making it hard to measure masculinity as a differentiating factor at the individual level.

\section{Table 2 Espoused National Cultural Values}

\begin{tabular}{|c|c|}
\hline $\begin{array}{ll}\text { Espoused } & \text { National } \\
\text { Cultural Value } & \end{array}$ & Definition \\
\hline Power Distance & $\begin{array}{l}\text { Degree to which large } \\
\text { differentials of power and } \\
\text { inequality are accepted as } \\
\text { normal by the individual. } \\
\text { Power distance will condition } \\
\text { the extent to which the } \\
\text { employee accepts that his/her } \\
\text { superiors have more power. }\end{array}$ \\
\hline Uncertainty Avoidance & $\begin{array}{l}\text { Uncertainty avoidance is the } \\
\text { level of risk accepted by the } \\
\text { individual, which can be } \\
\text { gleaned by his/her emphasis } \\
\text { on rule obedience, ritual } \\
\text { behaviour, and labour } \\
\text { mobility. This dimension } \\
\text { examines the extent to which } \\
\text { one feels threatened by } \\
\text { ambiguous situations. }\end{array}$ \\
\hline Individualism/Collectivism & $\begin{array}{l}\text { Degree to which the } \\
\text { individual emphasises his/her } \\
\text { own needs as opposed to } \\
\text { group needs and prefer to act } \\
\text { as an individual rather than as } \\
\text { a member of a group. }\end{array}$ \\
\hline
\end{tabular}

(Srite and Karahanna 2006)

It is posited that ERP users with espoused power distance cultural values are likely to play a role in their perceptions toward the software quality of ERP. The source of such an influence is probably related to how these ERP users are able to maintain their power, control and social status over employees during their use of the system. For example, if an ERP system provides integration that takes these privileges away from such users, users with high espoused power distance cultural values are likely to develop a negative attitude towards the software quality features. As psychological contract theory suggests, once a psychological breach occurs, it makes ERP users compare their past and present experience during their use of the software. Thus, these ERP users with such cultural traits perceive this breach as a 'violation' that causes them to devalue the software quality characteristics. Then, it is possible to hypothesise that ERP users with espoused power distance cultural values will vary in their perceptions of the software quality of ERP.

H1: The level of espoused power distance cultural values influence ERP user perceptions of software quality attributes.

Depending on the level of espoused uncertainty avoidance cultural values, it is posited that ERP users will vary in their 


\section{Dr. Hisham Al hirz / Perceived Individual Cultural Values and Erp Users: The Case of Saudi Arabia}

perceptions of software quality of ERP. Such variation can be explained in light of what ERP normally causes during and after its implementation, such as job skills change (Klaus and Blanton 2010). For example, ERP users with high espoused uncertainty avoidance cultural values are likely to feel nervous, stressed, and anxious about unstructured situations (Hofstede 2001). This, in turn, creates ERP users who are less comfortable with the level of integration, reliability or customisability of their software. However, it is difficult to determine the direction of such a relationship, due to contingent factors such as ERP implementation stage (Klaus and Blanton 2010), experience (Venkatesh and Bala 2008), and informational and normative influences (Srite and Karahanna 2006).

$\mathrm{H} 2$ : The level of espoused uncertainty avoidance cultural values influence ERP user perceptions of software quality attributes.

Recent thinking in psychology recognises the self as a powerful regulator of many aspects of human behaviour, such as perception, memory, emotion, motivation, human agency, and volition (Srite and Karahanna 2006). Those with an independent self-construal focus primarily on their own internal traits, skills, and attitudes as defining the self. However, those with an interdependent construal of self (collectivistic values) 'are motivated to belong and fit in rather than be unique, to promote others' goals rather than one's own' (Bond and Smith 1996, p. 126 cited in Srite and Karahanna 2006). This, in fact, suggests that ERP users with espoused individualistic/collectivistic cultural values are likely to perceive their software quality differently, because 'individualists' behaviour is more closely linked to attitudes and collectivists' behavior is more closely linked to norms'. If this is the case, such a relationship is perhaps dependent upon whether ERP users with individualistic and collectivistic cultural values perceive and interpret psychological contract breach as a violation of their cultural traits. In both cases, it is posited that the level of individualistic and collectivistic cultural values will influence ERP user perceptions of software quality attributes.

H3: The level of espoused individualistic and collectivistic cultural values influence ERP user perceptions of software quality attributes.

However, in the D\&M IS Success Model, Delone and Mclean (2003) propose three dimensions to measure quality: system quality, measuring technical success; information quality, measuring semantic success; and service quality, measuring the services of the IS function. As Delone and Mclean explain (2003), even though 'a claim could be made that "service quality" is merely a subset of the model's "system quality," the changes in the role of IS over the last decade argue for a separate variable - the "service quality" dimension'. The aim of our study, however, is not to explain these dimensions and their interrelationship. Rather, we hope to stress items that influence and explain perceived user satisfaction which in turn impact symbolic adoption that is defined as the metal acceptance of system users (Nah, Tan et al. 2004). In addition to this, we also seek to explain the relationship of perceived software quality, satisfaction and symbolic adoption in light of the framework of Baggozzi (2007) on behavioural adoption of IS.

Based on Bagozzi's framework, shown above in Figure 2, ERP users are influenced by how their goal desire is set (A). ERP users, for example, seek IS that allows them perceive relative advantages associated with their software as being integrated, reliable, and customisable (e.g., perceived software quality). Relying on how these characteristics are perceived, this is likely to determine the action desire (B) of ERP users. Therefore, this makes ERP users develop favourable attitudes towards their behaviour (e.g., perceived user satisfaction). However, self-regulation (C) moderates the influence of goal desire on action desire (Bagozzi 2007). Level of experience, personal traits and routine usage of IS, for example, can be seen as a reflexive self-regulation that influences goal desire and action desire of user behaviours of ERP. As a result, ERP users strive to achieve their action intention that leads to the adoption of ERP systems (D) (e.g., symbolic adoption). Therefore, the following hypotheses are posited:

H4: Perceived software quality influence perceived user satisfaction.

H5: Perceived user satisfaction influence symbolic adoption of ERP users.

\section{Method}

To test the hypotheses, data that was originally collected in a research project for a $\mathrm{PhD}$ thesis in a related area were used (Alhirz 2014). The data were collected using a combination of paper-based and email-based surveys of persons in organisations in Saudi Arabia implementing or using ERP systems. The participants worked in organisations included banking, telecommunication, manufacturing, and the petroleum industry. The number of questionnaires returned was 297, out of almost 350 people who received them. After removing incomplete surveys and duplicated email-based surveys, 230 questionnaires were available for data analysis. It is common in the Middle East industries to employ some foreign workers in addition to actual citizens, therefore, to get a realistic picture of ERP adoption, no differentiation was made between foreign and local employees in the sample. Table 3 presents the demographic characteristics of the survey subjects.

\section{Table 3 Demographic Characteristics of Respondents}

\begin{tabular}{|l|l|l|}
\hline $\begin{array}{l}\text { ERP } \\
\text { employees }\end{array}$ & Category & $\begin{array}{l}\text { Percentage } \\
(\%)\end{array}$ \\
\hline \multirow{2}{*}{ Gender } & Male & $98.2 \%$ \\
\cline { 2 - 3 } & Female & $1.8 \%$ \\
\hline \multirow{4}{*}{ Age } & $\leq 29$ years & $28.4 \%$ \\
\cline { 2 - 3 } & $30-49$ years & $62.4 \%$ \\
\cline { 2 - 3 } & $\geq 50$ years & $9.2 \%$ \\
\hline \multirow{2}{*}{$\begin{array}{l}\text { Education } \\
\text { level }\end{array}$} & $<$ bachelor degree holders & $42.7 \%$ \\
\cline { 2 - 3 } Organisatio & $\geq$ bachelor degree holders & $57.3 \%$ \\
\hline
\end{tabular}


Dr. Hisham Al hirz / Perceived Individual Cultural Values and Erp Users: The Case of Saudi Arabia

\begin{tabular}{|l|l|l|}
\hline $\mathrm{n}$ size & employees $)$ & \\
\cline { 2 - 4 } & $\begin{array}{l}\text { small/medium enterprises } \\
(\mathrm{SMEs})(<250 \text { employees })\end{array}$ & $26.1 \%$ \\
\hline \multirow{2}{*}{$\begin{array}{l}\text { ERP user } \\
\text { level }\end{array}$} & \begin{tabular}{l} 
ERP routine users \\
\cline { 2 - 4 } developers
\end{tabular} & $63.1 \%$ \\
\hline
\end{tabular}

Appendix 1 shows the items used in this research along with their sources. A five point Likert scale was used to measure each item.

\section{Results}

The research model was analysed using IBM SPSS AMOS, which is a powerful tool for structural equation modelling that allows the simultaneous analysis of indicator variables (Tabacknick and Fidell 2007).

\section{Assessing Reliability and Validity}

Hofstede's cultural measures have been widely validated in IS research (Srite and Karahanna 2006; Hsu, Hsu et al. 2010; Hwang 2012). This model gives different weights to different items (Hofstede, Hofstede et al. 2008); since the standard reliability calculations do not take into consideration the differential weights of items, the reliability and validity analysis looked at the items of the remaining variables.

SPSS generates Bartlett's test of sphericity and the KaiserMeyer-Olkin (KMO), as these tests assess the inter-correlation among items and the sampling adequacy. Our data shows that the KMO measure for this sample is acceptable (0.82) and the significance level of the Bartlett's test $(p<0.001)$ indicates that the overall inter-correlation assumptions are met. Appendix 2 shows the factor analysis conducted, and the alignment of items. Table 4 indicates the convergent validity of the research construct, and the data indicate that the measures are acceptable in terms of their reliability as indexed by Cronbach's alpha and Composite Reliability (CR) (Nunnally 1967). Therefore, the convergent and discriminant validity of our data were adequate for this exploratory study.

Table 4 Assessment of internal consistency of the construct

\begin{tabular}{|l|l|l|}
\hline Construct & Cronbach's alpha & CR \\
\hline SA & 0.875 & 0.877 \\
\hline SQ & 0.762 & 0.733 \\
\hline US & 0.768 & 0.771 \\
\hline
\end{tabular}

\section{The Structural Model}

The model yielded a Chi-squared value of 19.959, with 7 degrees of freedom and a p-value of 0.006. This did not indicate a good model fit; however, the model was further examined using other goodness of fit measures (Byrne 2010), as shown in Table 5 shows that the results, particularly $\chi^{2 / \mathrm{df}}$ and RMSEA, confirm that the responses of participants support the theoretical and conceptual distinctions of all the variables proposed in this study. Therefore, the data can be applied for further analysis and discussion as in the next section.
Table 5 Goodness of Fit Measure of the Research Model

\begin{tabular}{|l|l|l|}
\hline $\begin{array}{l}\text { Goodness-of- } \\
\text { fit measures }\end{array}$ & $\begin{array}{l}\text { Recommended value } \\
\text { for p (Hsieh and } \\
\text { Wang 2007) }\end{array}$ & $\begin{array}{l}\text { Value obtained } \\
\text { for the model }\end{array}$ \\
\hline Chi-squared & $\mathrm{P}>0.05$ & $\mathrm{P}<0.001$ \\
\hline Relative $\mathrm{x}^{2}$ & $<3.00$ & 2.815 \\
\hline CFI & $\geq 0.9$ & 0.89 \\
\hline TLI & $\geq 0.9$ & 0.68 \\
\hline RMSEA & $<0.10$ & 0.090 \\
\hline
\end{tabular}

Table 6 shows the results with respect to the hypotheses. The level of power distance $(\beta=-0.006 ; p=0.037)$ shows a negative and significant influence on user perceptions of software quality of ERP, and therefore H1 is supported for ERP. The level of uncertainty avoidance $(\beta=0.006 ; \mathrm{p}=$ 0.027) shows significant and positive influence on user perceptions of software quality of ERP and hence $\mathrm{H} 2$ is supported. The level of individualism ( $\beta=0.002 ; p=0.559)$, however, shows non-significant influence and therefore $\mathrm{H} 3$ is rejected. User perceptions of software quality of ERP $(\beta=$ 0.415; $\mathrm{p}<0.001$ ) shows significant influence on perceived user satisfaction with ERP and therefore $\mathrm{H} 4$ is supported. Finally, perceived user satisfaction $(\beta=0.494 ; \mathrm{p}<0.001)$ also shows significant influence on the symbolic adoption of ERP users and therefore H5 is supported.

\section{Table 6 Results of testing}

\begin{tabular}{|l|l|l|l|}
\hline Hypotheses & $\begin{array}{l}\text { Regression } \\
\text { coefficient }(\beta)\end{array}$ & Sig & Results \\
\hline H1 & -0.006 & 0.037 & supported \\
\hline H2 & 0.006 & 0.027 & supported \\
\hline H3 & 0.002 & 0.559 & non-supported \\
\hline H4 & -0.415 & $<0.001$ & supported \\
\hline H5 & 0.494 & $<0.001$ & supported \\
\hline
\end{tabular}

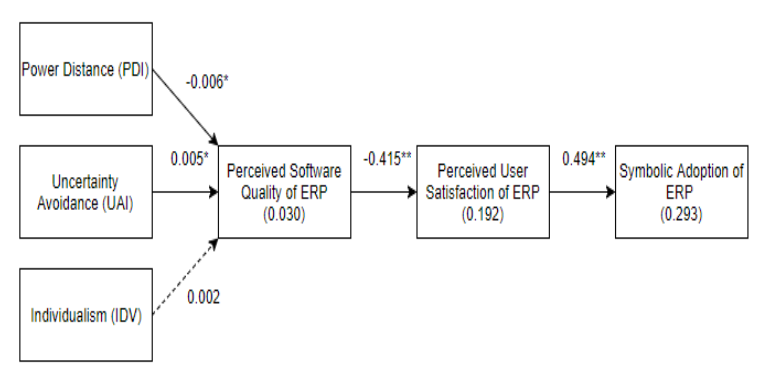

Figure 4 Key Findings (Continuous arrows show significant paths $(* * p \leq 0.01 ; * p \leq 0.05)$ and dotted arrows show nonsignificant paths $(\mathrm{p}>0.05))$

\section{Discussion and Findings}

The results show that the level of espoused power distance cultural values relatively influence user perceptions of software quality, in relation to data integration, system reliability and customisability. On the one hand, the significant relationship of $\mathrm{H} 1$ indicates that the sampled ERP users stressed these quality attributes as factors influencing their behavioural adoption at individual levels. The significant 


\section{Dr. Hisham Al hirz / Perceived Individual Cultural Values and Erp Users: The Case of Saudi Arabia}

negative relationship, on the other hand, indirectly shows that the level of espoused power distance cultural values were more likely to cause a problematic behavioural adoption among ERP users. The reason is related to how ERP users with high level of power distance cultural values perceived control over their systems, for example, the extent to which the level of data integration or system customisation, more or less changed their privileges, such as data access and input, and control power. Therefore, ERP users with a high level of power distance cultural values perceived ERP adoption as threat to their social status within an organisational context. This finding is consistent with Klaus and Blanton (2010). It is also further confirmed by Hossain, Bala and Bhagwatwar (2011) who suggest that employees in Saudi Arabia have an authority issue that is related to executing business processes in the post-implementation stages, such as stabilisation and improvement stage.

The results also show that the level of espoused uncertainty avoidance cultural values relatively influence user perceptions of software quality of ERP. It seems that the level of influence of espoused uncertainty avoidance on perceptions of software quality is different than its impact on ERP users during implementation. In other words, a low level of uncertainty avoidance traits seems to play an intrinsic role that encourages ERP users to explore their software quality characteristics. Having said this, a high level of uncertainty avoidance, therefore, prevented individuals from exploring additional features of the software. However, employees with high level of espoused uncertainty avoidance cultural values were apparently under the impression that they should develop an acceptable level of knowledge of how their ERP system functions. As this study of culture is different from most IT studies and ERP in particular (Srite and Karahanna 2006), one should take this difference into account when arguing such an influence of uncertainty avoidance on user perceptions of software quality and behavioural adoption of ERP.

However, ERP users with espoused individualistic and collectivistic cultural values did not show significant influence on user perceptions of software quality of ERP. Apparently, an ERP experience influenced how employees with individualistic or collectivistic values perceived their software quality features. This, however, suggests that the level of espoused individualism cultural values becomes less influential factor during the development of an attitude towards the software quality of ERP. Based on the psychological contract theory, it seems that employees with these cultural values do not perceive their software quality features as a psychological breach that makes them interpret their software quality outcomes as positive or negative. This, therefore, is likely to explain the non-significant influence of the espoused individualistic and collectivistic cultural values on their perceptions of software quality attributes. Srite and Karahanna (2006) explain that it is possible that espoused individualism/collectivism values are only distal antecedents of technology acceptance behaviour and that their effects are manifest via their impact on self-construal and its subsequent effect on behaviour'.

Finally, as these results show, perceived software quality attributes significantly influence perceived user satisfaction which in turn significantly influenced the mental acceptance of ERP users. It is obvious that data integration, reliability and customisation are influential dimensions of the software quality construct, which enable ERP users to develop favourable attitudes towards their mental acceptance of ERP. Such an attitude, therefore, is helpful to reduce internal tension between user mental acceptance and the actual behaviours of using technology. Based on these results and Hsieh and Wang (2007), ERP users are less likely to reject their systems since it is obligatory in nature; therefore, they use their system even before their mental acceptance of the technology occurs. As a result, they are likely to use a system that they mentally reject, creating 'a situation in which mental acceptance is in conflict with actual behaviour'. This, in turn, creates ERP users who are passively resistant to their systems. These users, thus, are less likely to extend their skills to use additional ERP functions.

\section{Conclusion}

Behavioural adoption is dynamic and requires a dynamic model that takes cultural, social and individual differences into account. It also requires a model that is able to distinguish between pre-implementation and post-implementation factors and their influences on behavioural adoption of ERP users. This paper confirms the framework of Bagozzi (2007) on behavioural adoption and acceptance of technology, and emphases the role of attitude as a vital element that drives behavioural adoption in non-voluntary contexts. This, therefore, contributes to the existing knowledge, bringing the attention of researchers toward deterministic behavioural adoption models that examine behaviour as 'cause and effect'. Researchers should probe into consolidating technology models based on the dynamic nature of user behaviours during different stages of ERP implementation.

This research paper also contributes to understand how to help ERP users who are operational and non-operational adapt to new technology. On the one hand, it provides them with a constructive understanding of factors influencing their mental acceptance to reduce their resistance, and therefore they can be more productive. It shows that the level of data integration, reliability and customisation are major determinant of user satisfaction at individual level and hence ERP users can be more adoptive and receptive to technology in mandatory context. On the other hand, it also enables ERP implementers to focus on the sources of user resistance based on individual differences along with cultural values. This allows them to create a less-resistant environment among ERP users.

\section{limitation}

One major limitation of this study is related to the crosssectional survey by which data collection was carried out at a single point of time. This, therefore, restricts the level of generalisability of the study's findings. Besides, the research model does not capture all factors that could influence user 


\section{Dr. Hisham Al hirz / Perceived Individual Cultural Values and Erp Users: The Case of Saudi Arabia}

adoption and acceptance of ERP. Our sample demographic largely reflects the traditional predominance of males in Saudi Arabian workforce. Insufficient female samples meant that we were not able to test for any significant differences in perceptions between the two genders.

\section{ACKNOWLEDGEMENTS}

The author would like to thank Al Yamamah University and Ministry of Education of Saudi for their support. He would also like to express his gratitude to those who supported this research, including all Anonymous reviewers with their valuable feedback.

\section{REFERENCES}

[1] Al-Jabri, I. M. and N. Roztocki (2015). "Adoption of ERP systems: Does information transparency matter?" Telematics and Informatics 32(2): 300-310.

[2] Alhirz, H. (2014). Influence of Cultural Factors on Behavioural Adoption and Acceptance of ERP Users in the Saudi Arabian Context, PhD Thesis, University of New England.

[3] Alhirz, H. and A. Sajeev (2015). "Do cultural dimensions differentiate ERP acceptance? A study in the context of Saudi Arabia." Information Technology \& People 28(1).

[4] Amoako-Gyampah, K. (2007). "Perceived usefulness, user involvement and behavioral intention: an empirical study of ERP implementation." Computers in Human Behavior 23(3): 1232-1248.

[5] Bagozzi, R. P. (2006). "Explaining Consumer Behavior and Consumer Action: From Fragmentation to Unit." Seoul Journal of Business 12(2): 11-143.

[6] Bagozzi, R. P. (2007). "The Legacy of the Technology Acceptance Model and a Proposal for a Paradigm Shift." Journal of the Association for Information Systems 8(4): 243-254.

[7] Boersma, K. and S. Kingma (2005). "Developing a cultural perspective on ERP." Business Process Management Journal 11(2): 123-136.

[8] Byrne, B. (2010). Structural Equation Modeling with AMOS, Taylor and Francis Group, LLC.

[9] Chadhar, M. A. and N. Rahmati (2004). Impact of National Culture on ERP Success. the First Australian Undergraduate Students' Computing Conference: 23-31.

[10] Davenport, T. H. (1998). "Putting the Enterprise into the Enterprise System." Harvard Business Review 75(4): 121-131.

[11]Davison, R. (2002). "Cultural complication of ERP: Valuable lessons learned from implementation expericens in parts of the world with different cultural heritages." Communication of the ACM 45(7): 109-111.

[12] Delone, W. H. and E. R. Mclean (2003). "The DeLone and McLean Model of Information Systems Success: A Ten-Year Update." Journal of Management Information
Systems 19(4): 9-30.

[13] Geertz, C. (1973). "1973The Interpretation of Cultures." New York: Basic.

[14]Hall, E. T. (1976). Beyond culture. New York, NY, Anchor.

[15] Hawari, A. a. and R. Heeks (2010). "Explaining ERP failure in a developing country: a Jordanian case study." Journal of Enterprise Information Management 23(2): 135-160.

[16] Hofstede (1991). Cultures and Organizations: Software of the Mind. Madenhead, UK, McGraw-Hill.

[17]Hofstede (2001). Culture's consequences: Comparing values, behaviors, institutions, and organizations across nations. . Thousand Oaks, CA, SAGE Publiscations, Inc.

[18] Hofstede, G. (1980)._Culture's consequences: International differences in work related values. Beverly Hill, , CA: Sage.

[19]Hofstede, G. and M. H. Bond (1988). "The Confucius connection: From cultural roots to economic growth." Organizational dynamics 16(4): 5-21.

[20] Hofstede, G., G. J. Hofstede, et al. (2008). "Values survey module 2008." URL: www.geerthofstede.nl/media/253/VSM08English.doc (Stand 30.06. 2010).

[21] Hossain, M. M., H. Bala, et al. (2011). "Untold Stories of ERP Systems Implementation: Role of Ownership and Governance, Scope Management, and Employee Empowerment."

[22] Hsieh, J. P.-A. and W. Wang (2007). "Explaining employees' Extended Use of complex information systems." European journal of Information Systems 16(3): 216-227.

[23] Hsu, Y., L. Hsu, et al. (2010). "A cross-cultural study on consumers' level of acceptance toward marketing innovativeness." Afr. J. Bus. Manage 4(6): 1215-1228.

[24]Hwang, Y. (2012). "End User Adoption of Enterprise Systems in Eastern and Western Cultures." Journal of Organizational and End User Computing (JOEUC) 24(4): 1-17.

[25] Jagoda, K. and P. Samaranayake (2017). "An integrated framework for ERP system implementation." International Journal of Accounting \& Information Management 25(1): 91-109.

[26] Kappos, A. and S. Rivard (2008). "A Three-Perspective Model of Culture, Information Systems and Their Development and Use." MIS Quarterly 32(3): 61-634.

[27] Klaus, H., M. Rosemann, et al. (2000). "What is ERP?" Information Systems Frontiers 2(2): 141-162.

[28] Klaus, T. and J. E. Blanton (2010). "User resistance determinants and the psychological contract in enterprise 


\section{Dr. Hisham Al hirz / Perceived Individual Cultural Values and Erp Users: The Case of Saudi Arabia}

system implementations." European journal of Information Systems 19(6): 625-636.

[29] Klaus, T., S. C. Wingreen, et al. (2010). "Resistant groups in enterprise system implementations: a Q-methodology examination." Journal of Information Technology 25(1): 91-106.

[30] Lachman, R. (1983). "Modernity change of core and periphery values of factory workers." Human Relations 36(6): 563-580.

[31] Lapointe, L. and S. Rivard (2005). "A Multilevel Model of Resistance to Information Technology Implementation." MIS Quarterly 29(3): 461-491.

[32] Lee, S.-G., S. Trimi, et al. (2013). "The impact of cultural differences on technology adoption." Journal of World Business 48(1): 20-29.

[33] Liang, H. and Y. Xue (2004). "Coping with ERP-related contextual issues in SMEs: a vendor's perspective." Journal of Strategic Information Systems 13 399-415.

[34] McCoy, S., D. F. Galletta, et al. (2007). "Applying TAM across cultures: the need for caution." European journal of Information Systems 16(1): 81-90.

[35] Molla, A. and I. Loukis (2005). Success and failure of ERP technology transfer: a framework for analysing congruence of host and system cultures, University of Manchester. Institute for development policy and management (IDPM).

[36] Nah, F. F.-H., X. Tan, et al. (2004). "An Empirical Investigation on End-Users' Acceptance of Enterprise Systems." Information Resources Management Journal 17(3): 32-32-51.

[37] Nunnally, J. C. (1967). Psychometric Theory, New York 1967.

[38] Rabaa'i, A. A. (2009). The impact of organisational culture on erp systems implementation: lessons from jordan. Proceedings of the Pacific Asia Conference on Information Systems 2009.

[39] Rajapakse, J. and P. B. Seddon (2006). ERP Adoption in Development Countries in Asia: A Cultural Misfit, The University of Melbourne, Australia. 2010.

[40] Saleh, M. F., M. Abbad, et al. (2013). "ERP Implementation Success Factors in Saudi Arabia." International Journal of Computer Science and Security (IJCSS) 7(1): 15-30.

[41] Shang, S. and P. B. Seddon (2000). A comprehensive framework for classifying the benefits of ERP systems. Americas Conference on Information Systems.

[42] Sheu, C., B. Chae, et al. (2004). "National differences and ERP implementation: issues and challenges." Omega 32(5): 361-371.

[43] Srite, M. and E. Karahanna (2006). "The Role of Espoused National Cultural Values in Technology
Acceptance." MIS Quarterly 30(3): 679-704.

[44] Sternad, S., M. Gradisar, et al. (2011). "The influence of external factors on routine ERP usage." Industrial Management \& Data Systems 111(9): 1511-1530.

[45] Straub, D., K. Loch, et al. (2002). "Toward a theory-based measurement of culture." Human factors in information systems: 61-82.

[46] Tabacknick, B. G. and L. S. Fidell (2007). Using Multivariate Statistics. Unitated State of America, Pearson Education, Inc.

[47] Tyler, T. R., E. A. Lind, et al. (2000). "Cultural values and authority relations: The psychology of conflict resolution across cultures." Psych. Pub. Pol. and L. 6: 1138-1164.

[48] Venkatesh, V. and H. Bala (2008). "Technology acceptance model 3 and a research agenda on interventions." Decision Sciences 39(2): 273-315.

[49] Venkatesh, V., J. Thong, et al. (2012). "Consumer acceptance and use of information technology: Extending the unified theory of acceptance and use of technology." MIS Quarterly 36(1): 157-178.

[50] Venkatesh, V. and X. Zhang (2010). "Unified Theory of Acceptance and Use of Technology: U.S. Vs. China." Journal of Global Information Technology Management 13(1): 5-27.

[51]Zhang, Z., M. K. O. Leeb, et al. (2005). "A framework of ERP systems implementation success in China: An empirical study." International Journal of Production Economics 98(1): 56-80.

\section{APPENDIX 1}

\begin{tabular}{|c|c|c|}
\hline & Items & Sources \\
\hline \multicolumn{2}{|c|}{ In an ideal job, how important it is for you to: } & \multirow{11}{*}{$\begin{array}{l}\text { Hofstede } \\
(2001)\end{array}$} \\
\hline CUL1 & $\begin{array}{l}\text { have a boss (direct superior) you can } \\
\text { respect }\end{array}$ & \\
\hline CUL2 & $\begin{array}{l}\text { be consulted by boss in decisions } \\
\text { involving your work }\end{array}$ & \\
\hline CUL3 & have security of employment & \\
\hline CUL4 & $\begin{array}{l}\text { have sufficient time for your } \\
\text { personal or home life }\end{array}$ & \\
\hline CUL5 & $\begin{array}{l}\text { have a job respected by your family } \\
\text { and friends }\end{array}$ & \\
\hline CUL6 & do work that is interesting & \\
\hline CUL7 & $\begin{array}{l}\text { How often, in your experience, are } \\
\text { subordinates afraid to contradict } \\
\text { their boss (or students their teacher) }\end{array}$ & \\
\hline CUL8 & $\begin{array}{l}\text { How often do you feel nervous or } \\
\text { tense? }\end{array}$ & \\
\hline CUL9 & $\begin{array}{l}\text { All in all, how would you describe } \\
\text { your state of health these days? }\end{array}$ & \\
\hline CUL10 & $\begin{array}{l}\text { One can be a good manager without } \\
\text { having a precise answer to every } \\
\text { question that a subordinate may }\end{array}$ & \\
\hline
\end{tabular}


Dr. Hisham Al hirz / Perceived Individual Cultural Values and Erp Users: The Case of Saudi Arabia

\begin{tabular}{|c|c|c|}
\hline & raise about his or her work & \\
\hline CUL11 & $\begin{array}{l}\text { An organization structure in which } \\
\text { certain subordinates have two } \\
\text { bosses should be avoided at all cost }\end{array}$ & \\
\hline CUL12 & $\begin{array}{l}\text { A company's or organization's rules } \\
\text { should not be broken not even when } \\
\text { the employee thinks breaking the } \\
\text { rule would be in the organization's } \\
\text { best interest }\end{array}$ & \\
\hline & & \multirow{4}{*}{$\begin{array}{l}\text { Delone } \\
\text { and } \\
\text { Mclean } \\
(1992)\end{array}$} \\
\hline PSQ1 & ERP allows data integration & \\
\hline PSQ2 & ERP is fast and responsive & \\
\hline PSQ3 & ERP allows for customisation & \\
\hline PUS1 & $\begin{array}{l}\text { ERP provides the precise } \\
\text { information needed }\end{array}$ & \multirow{4}{*}{$\begin{array}{l}\text { Doll and } \\
\text { Torkzade } \\
\text { h }(1989)\end{array}$} \\
\hline PUS2 & $\begin{array}{l}\text { The internal content provided by } \\
\text { ERP system meets my needs }\end{array}$ & \\
\hline PUS3 & $\begin{array}{l}\text { ERP provides reports that seem to } \\
\text { be exactly what is needed }\end{array}$ & \\
\hline PUS4 & ERP provides sufficient informaiton & \\
\hline SA1 & $\begin{array}{l}\text { I am enthusiastic about using the } \\
\text { ERP system }\end{array}$ & \multirow{3}{*}{$\begin{array}{l}\text { Venkates } \\
\text { h et al. } \\
(2004)\end{array}$} \\
\hline SA2 & $\begin{array}{l}\text { I am excited about using ERP in my } \\
\text { workplace }\end{array}$ & \\
\hline SA3 & $\begin{array}{l}\text { It is my desire to see full utilisation } \\
\text { and deployment of the ERP } \\
\text { system }\end{array}$ & \\
\hline
\end{tabular}

\section{APPENDIX 2}

\begin{tabular}{|l|l|l|l|}
\hline & \multicolumn{3}{l}{ Component } \\
\cline { 2 - 4 } & 1 & 2 & 3 \\
\hline SQ5 & -.037 & $\mathbf{. 6 8 5}$ & -.054 \\
\hline SQ6 & .002 & $\mathbf{. 8 3 8}$ & .040 \\
\hline SQ7 & .051 & $\mathbf{. 8 6 6}$ & .021 \\
\hline US1 & .217 & -.024 & $\mathbf{. 6 9 0}$ \\
\hline US2 & .144 & -.350 & $\mathbf{. 4 3 0}$ \\
\hline US3 & .054 & -.171 & $\mathbf{. 7 0 2}$ \\
\hline US4 & -.124 & .120 & $\mathbf{. 9 2 7}$ \\
\hline UA1 & $\mathbf{. 9 2 3}$ & .024 & .031 \\
\hline UA2 & $\mathbf{. 8 7 3}$ & .057 & .066 \\
\hline UA3 & $\mathbf{. 8 8 5}$ & -.058 & -.089 \\
\hline
\end{tabular}

